\title{
Social transformations of speech culture in information age
}

\author{
Artur Gudmanian ${ }^{1}$, Liubov Drotianko ${ }^{1}$, Sergiy Sydorenko ${ }^{1}$, Oksana Zhuravliova $^{1}$, Sergiy \\ Yahodzinskyi $^{1}$ \\ ${ }^{1}$ National Aviation University, Department of Philosophy, Kosmonavta Komarova ave. 1, Kyiv, \\ Ukraine
}

\begin{abstract}
The paper looks at the major technological, sociocultural and linguistic factors that are changing the nature of interpersonal communication in the Information Age, and some manifestations of these changes. Rapid progress of technology, above all, the advent of the Internet, brought about dramatic changes in the modes and parameters of human communication over the recent decades. New types of written communication arose and have firmly established themselves on the global scale - in social networks, chats, blogs, forums and various Internet communities. Having created unprecedented possibilities for connecting with people irrespective of their location, age or social status, innovative technology is at the same time challenging standards of communication ethics and speech culture. Sociocultural transformations in the modern society, democratization of social relations contribute to weakening of speech norms and deterioration of overall speech culture, especially among young people. The increasing role of English as a language of global communication and its reputation of the dominant language of new technology and virtual reality are inevitably influencing speech habits of the Internet users across the globe. The combined work of all these factors results in visible deterioration of speech culture, standardization and simplification of speech, elimination of cultural specificity, tendency to replace expressive language means with emoji, downgrading of style, defying norms of spelling, word use and grammar. Obvious irreversibility of technological progress and the growing share of life people spend online call on specialists from various related fields to continue comprehensive analysis of transformations of speech culture in the modern world with the aim to assess societal risks and work out timely and adequate countermeasures.
\end{abstract}

\section{Introduction}

Globalization processes are currently penetrating all spheres of social life worldwide, above all, through steady and inevitable advance of information and communication technology. The fact that essential transformations in the economic, social, political and intellectual domains of social life are to a major extent powered by the progress of science and technology has been emphasized by such theorists of the Information Age as Y. Masuda, D. Bell, A. Toffler and their followers. In view of the present-day objective 
tendencies of technological development, humankind is on irreversible move towards a unified global civilization, generating a uniform technology-dominated space [1, p. 145], which is opposed to political, cultural and other types of diversity. New information and communication tools based on computer technology increasingly facilitate global communication, which explains why our modern age is often called the age of mass communications.

\section{Aim}

Emergence and mass use of innovative means of communication produce an essential impact on language, contributing to the growth of global, or international, lexicons, bringing about modes of speaking, such as computer-speak or techno-speak, which rise above national languages and serve as a medium of specialist communication for technology-related people around the globe. At the same time, innovative technology is changing communication habits of all Internet-users, irrespective of their technological competence. Thus, a new communication ethos is evolving, which matches new reality of global communication. These developments cannot help affecting speech culture of the speakers actively engaged in ICT. The aim of this paper is to define the major social and cultural factors which cause changes in speech culture in the Information Age and look at some manifestations of these changes.

\section{Research methods}

Throughout cultural evolution of humankind, human speech, above all, human lexicon has been constantly changing to embrace innovations produced by the civilization, but the speed and scale of the change in the age of "information explosion" (Marshal McLuhan) are unprecedented. A dramatic impetus to the process was given by the need to develop artificial programming languages, which require a high degree of precision and completeness. These languages not only transform the natural language itself, but also its function in the process of using a computer as a communication tool. Mark Dery argues that in cyberculture computer managed to eliminate the traditional distance between word and action, as the function of words read on the computer screen is not so much to inform but to provoke action [2, p. 93]. This effect can be observed during flashmobs and other similar activities, especially among young people.

The culture of speech communication in the Information Age is generally based on the principles of semiotics, which arose as a full-fledged science in the second half of the previous century at the crossroads of such sciences as cybernetics, information theory and structural linguistics. That was the time of impressive developments in the field of mass media, which resulted in the transformation of modes of communication, through fast spread of interactivity in particular.

Our research makes use of sociocultural methodological approach, which gives a possibility to look at the specificity of communicative processes in social networks in the context of cultural transformations that have been underway in the globalized world since the late $20^{\text {th }}$ century. Besides, a prominent role is assigned to the method of culturalsemantic analysis, which enables us to study the changes in the cultural content of language means in communication between representatives of various cultures in social networks.

\section{Research results}


Emergence of the Internet opened a new epoch in the culture of communication, marked by development of social networks, which bring together representatives of various cultures from across the globe. New modes of intercultural communication unite people around the burning ecological, political, cultural problems of modern civilization, which demand the attention of the humanity irrespective of geographical borders. Communication is getting more and more democratic, accessible to vast numbers of people from different backgrounds, living on different continents.

On the other hand, people's increasing mobility facilitated by faster means of transportation and advanced transport networks removes spatial and temporal barriers in personal communication, makes people physically closer to each other, bringing about a vibrant convergence and mixing of cultures. These phenomena of today's world contribute to the shaping of a global mindset, form global mentality, and as a result, change people's speech, which is incorporating phenomena of other cultures popularized via global communication means. Global promotion of goods, services and values tends to employ a simple language - a language which guarantees the intended delivery of the commercial and cultural content without unnecessary complications.

An important role in modern communication processes, as the authors emphasized in one of the previous publications [3], belongs to mobile phones, which transmit not only sound, but also graphics and text. Mobile phones, indeed, revolutionized communication and gave birth to new modes of human interaction, for instance, texting. "From the beginning, text messaging has attracted considerable negative reaction in the public domain, including hype over its dangers to the language, to the mind and brain of users, and to standards of literacy" [4, p. 317]. Texting widely employs unusual spellings, abbreviations, acronyms, logograms and smileys. In a 2012 study published in the journal New Media \& Society, scientists at Wake Forest University discovered a connection between the use of SMS-abbreviations and the students' increasing inability to identify and use correct grammar [5]. There is a growing concern among the older intellectual elite that the language of the Internet is killing literary language and speech standards, that simplified forms of communication have supplanted eloquence and coherent argumentative discourse, and that conversation stopped being an art.

The global net is playing with words we know, constructing new lexemes, giving new meanings to the well-known words and changing their form. Over the recent decades, new technology and new modes of communication have enriched English (and many other languages of the world) with such neologisms as crowdsourcing, spam, flashdrive, homepage, blog, log-in, geobragging, malware, noob, app, ego surfer, to google, to skype, etc. In tune with the increasing speed of everyday life, the language of the Information Age readily welcomes acronyms, such as DVD, GPS, LOL, USB, PC, CD, URL, OMG, ROFL, $I M H O$, etc.

Such words as avatar, troll, mouse, virus, cookie, thumb-nail, icon, hack have acquired completely different meanings relating to the computer technology and the Internet. The verbs which for centuries characterized human activity, such as to sleep, to wake up, to freeze, to think, to shut down, to browse now commonly refer to the activities done by a computer or via computer. WorldWideWeb itself is a metaphorical nomination, representing virtual space inhabited by complex networks of channels for communication, transmission and receipt of information. The desire to increase the speed of communication brings to life distorted and minimalist spellings, such as thru for through, $u$ for you, $c$ for see, pls for please, dpt for department, info for information, etc. Exchanging messages on the Internet, young people often tend to deliberately change the word form, displacing letters, doubling them, etc., to achieve the effect of novelty and extra kink. An extreme example of such language is so called Padonkaffsky jargon (Russian: язык падонкафф) or Olbanian (олбанский), a cant language developed on the Runet. The users of the jargon, for instance, 
would replace «буква» with «букфа», «много букв» with «многа букафф», «красавчик» with «кросафчег», «давай» with «дафай», «автор» with «аффтар», etc.

In view of these dramatic transformations in the field of human communication, present-day scholars - linguists, sociologists, psychologists, philosophers, experts in culture - are trying to comprehend what is happening to the human culture in general and speech culture in particular in the age dominated by science and technology. It is becoming more and more difficult not to take into account network effects when assessing sociocultural, psychological and economic factors of social development. There is no avoiding the fact that people tend to spend increasingly more time on the net, transferring there part of their personal life, their job and their relationships (see the statistics in Fig. 1).

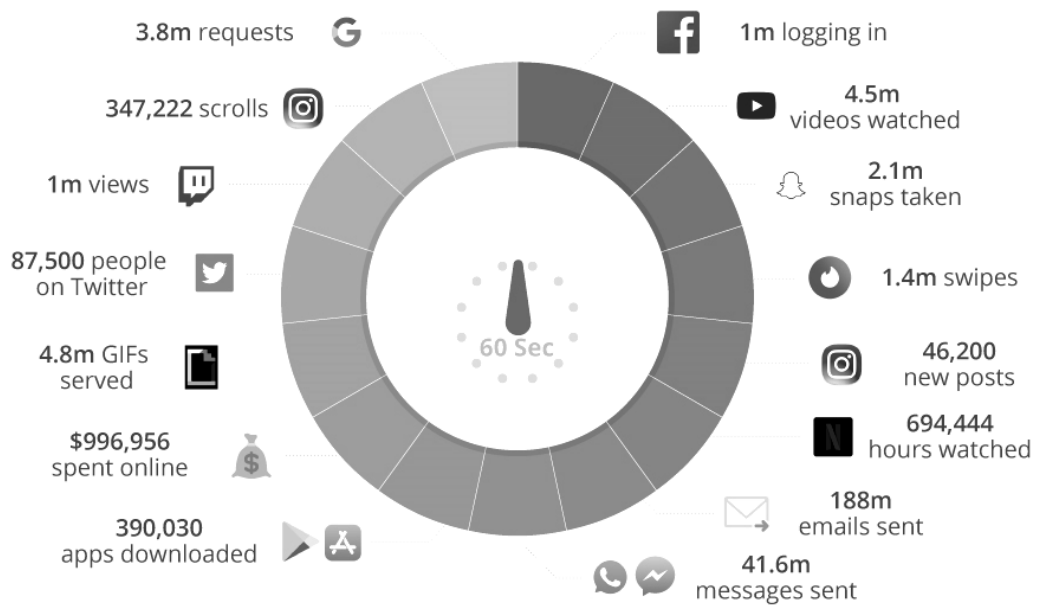

Fig. 1. Estimated data created on the Internet in one minute [6].

Of special concern is the deterioration of cultural and educational level of the young generation, a growing number of psychological problems and mental disorders resulting in a deviant behaviour of children, teenagers and young people. Analyzing the situation in Poland, Marian Bugajski emphasizes that it is not just the Internet but the mass media on the whole that affect the language of communication in modern society. The new mass media language is invading school, influencing speech habits not only of students but teachers too [7, p. 520]. Various subcultures characterized by their own jargons appear on radio and television and through mass media affect all layers of the society. The researcher is writing about gradual vulgarization of the present-day Polish language and the stylistic frailty of its users, who act both as agents and victims of this process [7, p. 521]. A similar situation is observed in Ukraine, especially in youth communication in social networks.

Having removed physical barriers in communication between people from different cultures, the Internet at the same time posed new challenges in intercultural perspective. Most researchers of the communicative processes in social networks acknowledge the dominant role of English as the language of intercultural communication between representatives of different cultures. However, the seeming absence of limits for communication carried on in "the global language" does not, in fact, eliminate understanding problems rooted in the specificity of national mentality, in the mindsets of people from different cultural backgrounds.

A. Wierzbicka reminds us about the direct correlation between how we speak and how we think [8, p. 21] - correlation, which since ancient times has been the object of speculation for philosophers, psychologists and linguists. A. Wierzbicka argues that the language of each culture is characterized by so called "key words", which are 
representative of this culture, the words which have a special significance and value in this given culture [8, p. 35]. And representatives of each culture, no matter how many languages they have mastered, hold on to the mindset exemplified by these key words. This leads us to the belief that even if people from different cultural backgrounds use English to communicate in social networks, they can hardly reach the level of complete mutual understanding.

Another communicative problem of Internet communication is the existence of various Englishes across the globe, which is the cause of transformations on all levels of intercultural communication (Table 1).

Table 1. Levels of intercultural communication.

\begin{tabular}{|c|c|c|c|}
\hline \multicolumn{3}{|c|}{ Levels of intercultural communication } \\
\hline $\begin{array}{c}\text { Individual } \\
\text { (interpersonal) }\end{array}$ & $\begin{array}{c}\text { Intercultural in small } \\
\text { and midsize groups }\end{array}$ & $\begin{array}{c}\text { Intercultural in } \\
\text { large communities }\end{array}$ \\
\hline $\begin{array}{c}\text { Subject - a person } \\
\text { Barriers - linguistic } \\
\text { and extralinguistic }\end{array}$ & $\begin{array}{c}\text { Subject - a small or midsize group } \\
\text { Barriers - absence of adaptation }\end{array}$ & $\begin{array}{c}\text { Subject } \text { large } \\
\text { communities } \\
\text { Barriers - national and } \\
\text { public interests }\end{array}$ \\
\hline
\end{tabular}

In her work Understanding Cultures through Their Key Words A. Wierzbicka writes about the differences between Australian English, American English, Indian English and other Englishes spoken in today's world, and asks a question: what are the grounds for believing that all of them are still one English language? [8, p. 41]. If languages serve sensitive indices to the cultures they belong to, the fact that these varieties of English are spoken by people from distinctively different cultures inevitably poses questions concerning the limits of language continuity. Even if users of social networks type the same English words, do they mean the same things? If people from the English-speaking countries who speak English as their first language admit misunderstandings caused by cultural differences, what about millions and millions who use English as their second language? Fig. 2 shows that in numbers of native speakers, English is by far outnumbered by Chinese and Spanish and is seriously challenged by Hindi and Arabic. That means that though global Internet communication seems to be English in its form, it is nevertheless permeated by various cultural and linguistic influences and implications.

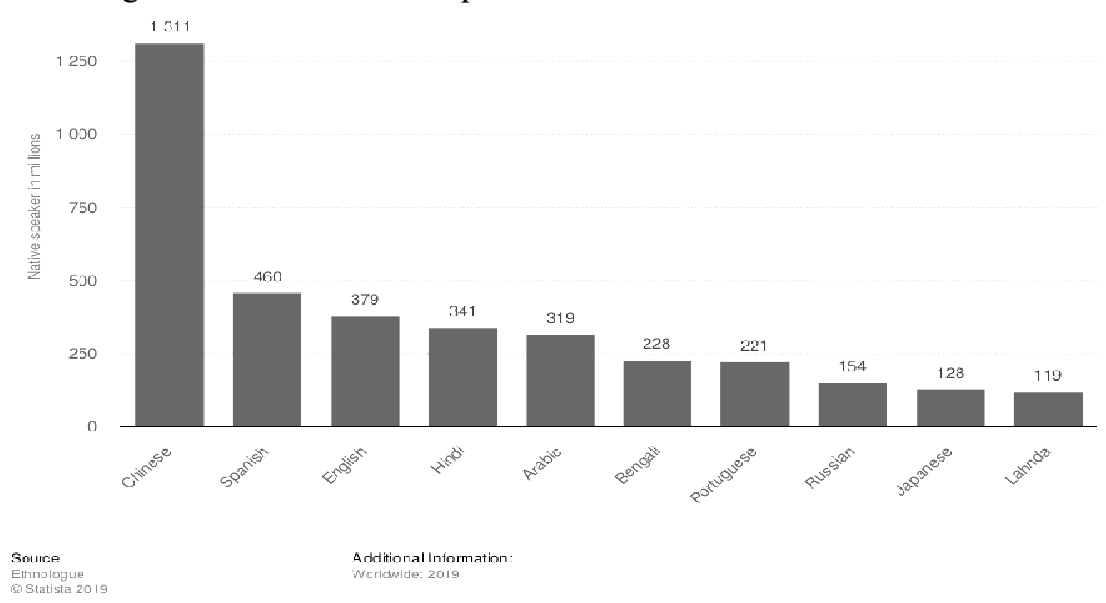

Fig. 2. The most spoken languages worldwide (native speakers in millions) [9].

Let us look at the word "friend", which is commonly used in Internet communication. On Facebook, friends are people associated with each other as contacts. Online English 
dictionaries give this meaning as a separate entry, to distinguish it from the classical "person you know well and like". Are people communicating on Facebook, who often have never met in person and are separated by great distances, really friends in the traditional meaning of this word? We know numerous cases when people who experience personal problems turn to their Facebook "friends" for support and receive inadequate advice resulting in a tragedy. What we mean is that in different cultures the same life problems are understood, approached and handled differently - the use of the same language cannot guarantee that your Facebook friend will see your situation with your eyes - moreover, some things that can hurt or abuse people in one culture may seem quite acceptable in another. For participants of intercultural communication to adequately understand the meaning and sense of the language means, they have to be aware of the mental specificity of communication in multicultural information space.

Impressive increase in the popularity of social networks observed in the recent decade is surely grounded on the obvious advantages these Internet communities bring to their members. At the same time, researchers of the Internet communication warn social network users about the existing and potential threats hidden in it. One of such threats is selfimposed isolation of people who spend hours in the net, living in cyberworld, engaging in virtual relationships and losing the knack of real communication, real feelings and real relations. When such people return to the reality and face challenges of actual life, they tend to feel helpless and annoyed at their inability to handle real problems.

Communication in social networks can hardly be imagined without emoji - various small images, symbols, or icons used to express emotions or deliver a message without words. Emoji have become an essential part of chat and email speech culture, carrying a significant semantic load. E. Ivanenko, M. Koretskaya and E. Savenkova make a good point observing that emoji appear when subjectiveness ceases to be interesting [10, p. 221]. They conclude that emoji have their own role in maintaining Internet communities. They are used to carry on light chats, to create the atmosphere of informality, intimacy, irony, and never - to convey genuine grief, fear or despair. Thus everything "touched" by an emoji becomes fun [10, p. 225].

Pictograms are a way for the Internet users to intentionally or unintentionally overlook or even defy social differences, as in the virtual space all its users presume to be equal. The new types of written communication which emerged with the Internet ignore grammar norms and spelling standards. Exaggerated role of emoji, which serve only as codes of emotions, not emotions themselves, in Internet conversations impoverishes not only the language of communication, but also the interlocutors' feelings - one of the essential things which makes us personalities. Thus smiley communication culture is transforming human community into a quasi-community, a simulacrum.

Concern about the state of the society's speech culture is expressed by the Russian linguist V. Karasik, who argues that the impact of the modern mass culture on communicative practices results in reduction of lexicon, simplification of grammar and increase in the share of the emotional content of utterance at the expense of its rational content, and also in vulgarization of speech [11, p. 90]. The researcher emphasizes that democratization of social relations has dramatically increased the role of everyday casual speech in the communicative space of the modern western civilization, in fact, made it a dominant mode of communication for the majority of speakers, whereas several decades ago this type of speaking was regarded by linguists as peripheral. In our opinion, simplification of speech in modern society and deterioration of its culture are caused not so much by democratization, but by the rapid progress of technologically new means of communication, which match the faster rate of life with faster communication technology.

However, the society should be aware that technology cannot be an excuse for substantial lowering of speech culture standards - maintaining these standards is of 
paramount importance, as speech culture exercises a profound influence on all kinds of social practices, education, science, politics, morals, art, etc., which by their inherent nature depend on language and speech. For the sake of its future, the society cannot afford deterioration of speech standards and romanticizing of illiteracy.

In this context, Marian Bugajski analyzes the phenomenon of snobbery in speech culture. He emphasizes the negative connotation of the word "snob", defining it as "a person who follows trendy behaviour, views and tastes of a certain group of people he/she strives to belong to" [7, p. 451]. In the context of speech practice, according to Marian Bugajski, the word 'snob' refers to people who indulge in using words of foreign origin with exaggerated admiration or deference. We believe that social networks breed speech snobbery. It is considered to be the right style in a chat to deliberately misspell words, insert profanities, etc., which allegedly makes the speaker accepted in certain circles of the Internet users. Snobbery as such and its traces in speech culture (or rather lack of culture) is the evidence of the speakers' low self-worth, their "provincialism complex" (M. Bugajski).

One more aspect of transformation of speech culture in the context of fast developing information and communication technology is featured by the Russian linguist T. Yudina. She is discussing the specifics of intercultural communication on the net, drawing attention to the anonymous character of such communication - its participants are people who often do not know each other personally, have never met in real life and do not mean to meet in the future [12, p. 657]. As a result, such communication is quite undemanding both intellectually and emotionally, the interlocutors know they do not bear responsibility for what they say and how they say it. After a chat is over, it is usually soon forgotten. This, in our opinion, may be one of the reasons why young generation's lexicon is losing literary words which convey sincere emotions and feelings and carry high spiritual and intellectual sense. Emotional and intellectual "shyness" in speech has its negative effect on personal relationships, breeds ersatz culture.

To be fair, if we look at the speech culture of the Internet communication beyond the level of everyday casual chats, there are still many domains which maintain definite standards. For instance, a professor and a student communicating on an e-learning course, in spite of all democratization processes, would commonly follow the norms of a codified literary speech. They would not use various emoji or logograms which are not related to the course material and they would carefully select words to deliver their message adequately and accurately.

Distance education, with all its obvious advantages, has also to a certain degree deprived the interaction between teacher and student of personal touch and spontaneous emotion. T. Yudina argues that such aspect as the teacher's personal charisma is being replaced with the parameter of the quality of the offered product and the form of its presentation, i.e. by the parameter of technical perfection and professionalism [12, p. 657]. In real class, teachers feel the audience and, if necessary, tune their delivery to the needs of the moment - with the help of a vivid example, additional argument, appropriate gesture, humour or eloquent pause. Devoid of instantaneous feedback, delivering a lecture before a camera is less emotional and more formal, it is usually not customized to a specific audience.

\section{Discussion}

Assessing the role of computer technology in social communication, there seems to be no other way but "to take the rough with the smooth". Objectively, the progress of science and technology has made communication easier, reduced the time and effort spent on preparation, transfer and receipt of information and getting the response. Modern ICT brought about the phenomenon of online communication, which revolutionized the 
decision-making process. Having accepted these obvious advantages, do we really have the right to grumble about wrong spellings, misplaced hyphens or the absence of punctuation marks?

M. Volodina writes that the spread of new mass media based on interactive, usermanaged information technology leads not only to changes in the forms and types of communication - it brings about changes in the role of natural languages in the overall semiotic system. Mass media - press, radio, television, cinema, the Internet - combining sound and written speech, still and moving images, involving music and body movements, make up a single semiotic assembly. This assembly comprises elements from different semiotic systems transformed to adapt to mass media communication tools. Such transformation generates texts of highest semiotic complexity, which may serve an interesting object of semiotic analysis [13, p. 13-14].

Globalization processes are permeated with interaction between various languages, and thus involve translation as a way of intercultural mediation [14]. Over the recent decades, translation has also been considerably affected by new technology - translator's work today, in view of the volumes of translated material and pressing deadlines, can hardly be imagined without computer assistance. As a process which creates a language product, translation has also fallen victim of the deterioration of speech culture discussed above, as machine translation will almost always produce a text of lower quality than a human translator. Machine translation "will still make some major mistakes that human translators never make, such as misspellings and mistranslations of proper nouns or rare terms, and the translation of sentences alone without regard to the context of their paragraphs or pages" $[15$, p. 4]. Such deficiencies may not be crucial for specialist texts, but in belles-lettres or journalistic style translation software so far fails when it comes to culture-specific words, tropes or occasional usages. Thus, machine translation cannot recreate the original in all its lexical and stylistic wealth, producing translations which are lexically inadequate, grammatically awkward and stylistically primitive.

\section{Conclusions}

The analysis of socio-cultural factors which cause the transformation of speech culture in the Information Age shows that the technological revolution in social communication is bringing about significant shifts in the nature of communication, giving rise to new types of human dependence on the technosphere. The artificial world created by human intellect begins to live its own life in the sense that people are constantly forced to adapt to new technologies, without which they cannot keep up with the accelerated rhythms of social life. Most people do not even fully realize how much their lives are being transformed by modern technology.

The large-scale advance of modern information and communication technologies in all social practices imbued with interpersonal communication inevitably leads to the modification of human speech. The positive or negative effects of using computer technology depend on the level of general culture of its users, as technical means play a supporting role in human communication processes. People cannot become mere supplements to technology, however "reasonable" it may be, and, moreover, they cannot transfer responsibility for deterioration of their speech culture on technological progress. Communication crisis in the society calls for reconsideration of its scale of values, so as not to yield to computer fetishism and not to lose important cultural benchmarks in the future.

\section{References}


1. L. Drotianko, S. Yahodzinskyi, Information environment as the intercultural communication space. Intern. Scie. Conf. SPbWORCE, 2016 «SMART City», 106 (2017) https://doi.org/10.1051/ matecconf/201710601006.

2. W.B. McGregor, Linguistics. An Introduction. London, New York, New Delhi, Sydney: Bloomsbury (2017)

3. P. Drexler, The Importance of Being Fluent in the Language of Texting. (2014) https://www.forbes.com/sites/peggydrexler/2014/06/23/the-importance-of-beingfluent-in-the-language-of-texting/\#308a5f566034.

4. S. Feldman, A Minute on the Internet in 2019. Statista (2019) https://www.statista.com/chart/17518/internet-use-one-minute.

5. The most spoken languages worldwide (native speakers in millions). Statista (2018) https://www.statista.com/statistics/266808/the-most-spoken-languagesworldwide/

6. Liddicoat, J. Anthony, Translation as intercultural mediation: setting the scene. Perspectives (2016) 24: 347-353. DOI: 10.1080/0907676X.2015.1125934

7. Z. Zong, Research on the Relations Between Machine Translation and Human Translation. J. of Phys.: Conf. Ser. 1087(6), 062046 (2018) DOI:10.1088/17426596/1087/6/062046. 